Jurnal Info Kesehatan

Vol 16, No.1, Juni 2018, pp. 106-118

P-ISSN 0216-504X, E-ISSN 2620-536X

Journal DOI: https://doi.org/10.31965/infokes

Website: http://jurnal.poltekeskupang.ac.id/index.php/infokes

R E S E A R C H

Open Access

\title{
Penyerapan Air Dan Kelarutan Bahan Semen Ionomer Kaca Sebagai Penutup Pit Dan Fisur Gigi
}

Emma Krisyudhanti

cantiktitik@rocketmail.com

Jurusan Keperawatan Gigi, Poltekkes Kemenkes Kupang

\begin{abstract}
Abstrak
Latar Belakang: Pit dan fissure sealant merupakan bahan yang sering digunakan untuk perawatan pencegahan, khususnya pada permukaan oklusal gigi yang rentan karies. Semua bahan restorasi yang berkontak dengan air akan mengalami 2 mekanisme, yaitu penyerapan air, yang menyebabkan pembengkakan matriks serta meningkatnya massa dan kelarutan air, yaitu terlepasnya komponen dari monomer yang tidak bereaksi dan menyebabkan berkurangnya massa. Tujuan: mengukur nilai penyerapan air dan kelarutan bahan semen ionomer kaca sebagai penutup pit dan fisur gigi. Metode: Peneltian ini merupakan jenis penelitian eksperimental. Hasil Penelitian: Nilai penyerapan air semen ionomer kaca sebagai penutup pit \& fisur gigi mengalami penurunan hingga hari kedua lalu meningkat hingga hari ketujuh, dengan rata-rata penyerapan air untuk perendaman selama 1 hari sebesar 42,68 $\mu \mathrm{g} / \mathrm{mm}^{3}$, 2 hari $40,53 \mu \mathrm{g} / \mathrm{mm}^{3}$ dan 7 hari $42,99 \mu \mathrm{g} / \mathrm{mm}^{3}$. Nilai kelarutan dalam air semen ionomer kaca sebagai penutup pit \& fisur gigi mengalami penurunan hingga hari kedua lalu meningkat hingga hari ketujuh, dengan rata-rata kelarutan bahan untuk perendaman selama 1 hari sebesar $41,46 \mu \mathrm{g} / \mathrm{mm}^{3}$, 2 hari $39,39 \mu \mathrm{g} / \mathrm{mm}^{3}$ dan 7 hari $41,91 \mu \mathrm{g} / \mathrm{mm}^{3}$. Kesimpulan: Tidak ada perbedaan yang signifikan untuk nilai penyerapan air dan kelarutan bahan selama masa perendaman 1, 2 dan 7 hari. Disarankan agar dalam pengaplikasian semen ionomer kaca sebagai penutup pit dan fisur gigi harap diperhatikan dalam pemberian varnish atau pelindung agar mengurangi terjadinya penyerapan air dan kelarutan bahan. Selain itu, pit dan fisur gigi yang sudah diberi penutup, hendaknya dikontrol 3 bulan kemudian untuk mengetahui apakah penutupnya masih utuh atau sudah rusak maupun lepas. Disarankan pula agar ada penelitian lanjutan untuk mengetahui nilai penyerapan air dan kelarutan bahan jika direndam di dalam saliva buatan selama lebih dari 7 hari.
\end{abstract}

Kata kunci: Penyerapan Air, Kelarutan Bahan, Semen Ionomer Kaca, Penutup Fissure Gigi 


\title{
Water Absorption and Solubility of Glass Ionomer Cement as a Cover for Pit and Tooth Physical
}

\begin{abstract}
Background: Pit and fissure sealants are materials that are often used for preventive maintenance, especially on occlusal surfaces of teeth that are susceptible to caries. All restoration materials that come into contact with water will experience 2 mechanisms, namely the absorption of water, which causes matrix swelling and increased mass and water solubility, namely the release of components from unreacted monomers and causing reduced mass. Objective: Measure the value of water absorption and solubility of glass ionomer cement as a cover of the pit and fissure of the tooth. Methods: This research is experimental research. Research Results: The absorption rate of glass ionomer cement as a cover of dental pit \& fissure decreased until the second day and increased until the seventh day, with an average absorption of water for 1-day immersion of $42.68 \mu \mathrm{g} / \mathrm{mm}^{3}, 2$ days $40,53 \mu \mathrm{g} / \mathrm{mm}^{3}$ and 7 days $42.99 \mu \mathrm{g} / \mathrm{mm}^{3}$. Solubility value in water of glass ionomer cement as a cover of dental pit \& fissure decreased until the second day then increased until the seventh day, with an average solubility of material for immersion for 1 day at $41.46 \mu \mathrm{g} / \mathrm{mm}^{3}$, 2 days $39.39 \mu \mathrm{g} / \mathrm{mm}^{3}$ and 7 days $41,91 \mu \mathrm{g} / \mathrm{mm}^{3}$. Conclusions: It was said that there was no significant difference in the value of water absorption and solubility of materials during the immersion period of 1,2 and 7 days. It is recommended that in the application of glass ionomer cement as a cover of dental pits and fissures, please note in the provision of varnish or protector to reduce the occurrence of water absorption and solubility of the material. In addition, the pit and fissure of the tooth that has been covered should be controlled 3 months later to find out if the cover is still intact or has been damaged or loose. It is also recommended that there is further research to determine the value of water absorption and solubility of ingredients if soaked in artificial saliva for more than 7 days.
\end{abstract}

Keywords: Water absorption, Solubility of materials, Glass ionomer, Fissure of the tooth

\footnotetext{
'Correspondence: cantiktitik@rocketmail.com

Present Address: Jurusan Keperawatan Gigi, Poltekkes

Kemenkes Kupang, Kupang City, Indonesia.
}

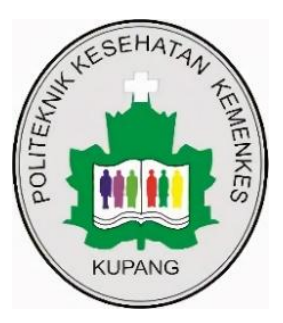

CThe Author(s) 2018. This article is distributed under the terms of the Creative Commons Attribution 4.0 International License (http://creativecommons.org/licenses/by/4.0/), which permits unrestricted use, distribution, and reproduction in any medium, provided you give appropriate credit to the original author(s) and the source, provide a link to the Creative Commons license, and indicate if changes were made. The Creative Commons Public Domain Dedication waiver (http://creativecommons.org/publicdomain/zero/1.0/) applies to the data made available in this article, unless otherwise stated. 


\section{PENDAHULUAN}

Pada permukaan oklusal dari gigi posterior terdapat suatu daerah yang dalam dan berlika-liku, daerah ini disebut sebagai pit dan fisur gigi. Pit dan fisur gigi ini dikelilingi oleh tonjolan yang disebut fossa. Daerah pit dan fisur yang dalam seringkali tidak dapat dijangkau oleh bulu sikat gigi atau dental floss sehingga dapat menjadi tempat berkembangnya bakteri kariogenik yang dapat menyebabkan karies gigi (Anonim, 2008).

Karies gigi adalah kehilangan kronis yang berkelanjutan dari ion mineral pada email atau permukaan akar (demineralisasi) yang umumnya distimulasi oleh kehadiran flora bakteri dan produk-produknya (Mount, G.J dan Hume, W.R., 2005). Karies disebabkan oleh banyak faktor, antara lain bakteri Streptococcus mutans, retensi dan kandungan plak akibat makanan yang lengket, diet makanan yang tinggi karbohidrat, saliva yang memiliki flow dan kemampuan buffering yang rendah serta kurangnya pemaparan fluoride (Mount, G.J dan Hume, W.R., 2005). Karies dapat pula menyebabkan berbagai hal, seperti gigi ngilu, abses, gangren pulpa, penurunan kualitas hidup, sampai serangan jantung akibat infeksi lokal. Salah satu tindakan pencegahan kariees adalah melalui upaya penutupan pit dan fisur gigi.

Ada beberapa kriteria pit dan fisur yang perlu dilapisi, yaitu fossa harus telah erupsi seluruhnya, ada kontak permukaan oklusal yang utuh dengan permukaan gigi antagonisnya yang karies atau terestorasi, kavitas kelas 1 yang telah bebas karies dan fossa yang terisolasi dengan baik dari fossa lainnya (Harris, N.O, Garcia, F.G., 2004).

Material penutup pit dan fisur (sealant) terdiri dari berbagai macam bahan, namun yang paling populer adalah yang terbuat dari resin komposit dan dari semen ionomer kaca. Resin komposit sebagai sealant dalam penggunaannya harus dilakukan etsa terlebih dulu untuk mendapatkan ikatan mikromekanik dengan email. Namun sebelumnya permukaan oklusal harus bebas dari debris makanan (Mount, G.J dan Hume, W.R., 2005). Semen ionomer kaca sebagai sealant dalam penggunaanya tidak memerlukan etsa terlebih dulu, hanya perlu dilakukan tindakan penghilangan smear layer menggunakan suatu conditioner yang bertujuan untuk meningkatkan perlekatan bahan terhadap struktur gigi (Baum, L., 1997).

Suatu bahan penutup pit \& fisur gigi yang baik memiliki nilai penyerapan air 
dan kelarutan bahan yang sekecil mungkin, karena nilai penyerapan air dan kelarutan bahan dalam air yang besar dapat menyebabkan efek merugikan, seperti perubahan dimensi, kehilangan integritas tepi, staining, bahkan dapat menyebabkan kegagalan restorasi. Penyerapan air dan kelarutan bahan mempengaruhi sifat mekanis, seperti kelenturan, kekerasan, stanilisasi mekanis serta biokompatibilitas material, seperti menstimulasi pertumbuhan bakteri sekitar restorasi (Hansel dkk, 1998 dalam Veranes, 2006) dan reaksi alergi pada beberapa orang (Spahl dkk, 1994 dalam Veranes, 2006).

Bahan penutup pit \& fisur gigi yang digunakan harus memenuhi standar ISO 4049. Standar ISO 4049 menetapkan bahwa nilai maksimum untuk penyerapan air adalah $40 \mu \mathrm{g} / \mathrm{mm}^{3}$ dan kelarutan bahan dalam air adalah $7,5 \mu \mathrm{g} / \mathrm{mm}^{3}$. Penelitian Hertanto (2008) menyatakan bahwa nilai penyerapan air resin sebagai penutup pit dan fisur adalah sebesar 37,4 $\mu \mathrm{g} / \mathrm{mm}^{3}$ dan nilai kelarutan bahannya sebesar $4,5 \mu \mathrm{g} /$ $\mathrm{mm}^{3}$, yang berarti nilainya lebih rendah daripada nilai yang ditetapkan oleh ISO sehingga memenuhi syarat untuk digunakan di klinik. Penelitian Ghanim (2009) menunjukkan hasil bahwa nilai penyerapan air semen ionomer kaca sebagai bahan tumpatan adalah sebesar $219,17 \mu \mathrm{g} / \mathrm{mm}^{3}$ dan nilai kelarutan bahannya sebesar 44,82 $\mu \mathrm{g} / \mathrm{mm}^{3}$, sedangkan penelitian untuk mengukur nilai penyerapan air dan kelarutan bahan semen ionomer kaca sebagai bahan penutup pit \& fisur gigi belum pernah dilakukan.

Berdasarkan latar belakang diatas, maka tujuan penelitian ini adalah untuk mengukur nilai penyerapan air dan kelarutan semen ionomer kaca sebagai penutup pit \& fisur gigi serta untuk membandingkan nilai penyerapan air dan kelarutan semen ionomer kaca sebagai penutup pit \& fisur gigi yang direndam selama 1, 2, dan 7 hari. Adapun manfaat yang dapat diperoleh dari penelitian ini, adalah bagi peneliti diharapkan hasil penelitian ini dapat menjadi masukan dalam menentukan pilihan penggunaan bahan penutup pit \& fisur gigi yang efektif berada dalam rongga mulut, bagi Klinik Jurusan Keperawatan Gigi diharapkan hasil penelitian ini dapat menjadi masukan dan tambahan pustaka bagi dosen, Clinical Instructure dan mahasiswa Jurusan Keperawatan Gigi, terutama dalam perawatan penutupan pit dan fisur gigi dan bagi keilmuan, diharapkan hasil penelitian ini dapat menjadi data awal tentang penyerapan dan kelarutan semen ionomer 
kaca sebagai bahan penutup pit dan fisur gigi.

\section{METODE PENELITIAN}

Peneltian ini merupakan jenis penelitian eksperimental laboratorik rancangan acak lengkap. Sampel yang digunakan adalah sealant dari semen ionomer kaca merek GC Fuji VII yang diproduksi oleh GC Japan. Jumlah sampel yang digunakan adalah sebanyak 18 buah dengan 6 sampel untuk setiap waktu perendaman (perendaman selama 1 hari, 2 hari dan 7 hari). Kriteria sampel, yaitu berbentuk silindris berukuran diameter 15 $\mathrm{mm} \times$ tebal $1 \mathrm{~mm}$, permukaan atas dan bawah sampel licin serta tidak ada retakan atau patahan pada sampel. Adapun cara kerja pada penelitian ini adalah dengan urutan sebagai berikut:

a. Material sealant semen ionomer kaca dimanipulasi sesuai petunjuk pabrik dan membuat enam spesimen berukuran diameter $15 \mathrm{~mm}$ dan tebal 1 $\mathrm{mm}$ dibuat untuk setiap waktu perendaman

b. Cetakan diisi sedikit demi sedikit dengan hasil adukan semen ionomer kaca dan ditumpuk di antara 2 pelat gelas untuk mengeluarkan material berlebihan c. Setelah mengeras, spesimen dikeluarkan dari cetakan masingmasing.

d. Spesimen dimasukkan ke dalam desikator bersuhu $37^{\circ} \mathrm{C}$ selama 22 jam dan kemudian dimasukkan ke desikator lainnya yang bersuhu $23^{\circ} \mathrm{C}$ selama 2 jam. Spesimen ditimbang dengan timbangan presisi $0,1 \mathrm{mg}$. Pengukuran dilakukan berulangkali sampai massa konstan didapatkan (M1).

e. Spesimen dimasukkan ke dalam $40 \mathrm{ml}$ aquabides dan disimpan pada desikator bersuhu $37^{\circ} \mathrm{C}$ selama 1 hari, 2 hari dan 7 hari.

f. Pada akhir setiap waktu perendaman, spesimen dipindahkan dari aquabides, dikeringkan dengan kertas penghisap dan digetarkan di udara selama 15 detik. Spesimen ditimbang untuk mendapatkan M2.

g. Spesimen direkondisi dengan dimasukkan ke dalam desikator bersuhu $37^{\circ} \mathrm{C}$ selama 22 jam dan kemudian dimasukkan ke dalam desikator lainnya yang bersuhu $23^{\circ} \mathrm{C}$ selama 2 jam dan prosedur ini diulang pada satu hari berikutnya, kemudian massa ditimbang berulangkali sampai massa konstan didapatkan (M3). 
Nilai dari water sorption dan solubility dinyatakan dalam $\mu \mathrm{g} / \mathrm{mm}^{3}$ dan dihitung dengan persamaan berikut:

$$
\begin{aligned}
& \text { Wsp }=\text { M2 }- \text { M3/ V } \\
& \text { Wsl }=\text { M1 }- \text { M3/ V }
\end{aligned}
$$

M1 adalah massa sebelum direndam dalam aquabides. M2 adalah massa spesimen setelah perendaman dalam aquabides, dalam satuan miligram. M3 adalah massa setelah dilakukan proses perendaman dan pengeringan, dalam satuan miligram. V adalah volume dari spesimen dalam $\mathrm{mm}^{3}$. Volume spesimen dihitung dengan rumus volume silinder (Archegas dkk, 2008; Keyf dkk, 2006; Gerdolle dkk, 2008; Cefaly dkk, 2006). Data yang diperoleh akan dianalisis dengan uji Kruskal

Wallis.

\section{Skema 1. Alur Penelitian}

membuat 18 cetakan berdiameter $4 \mathrm{~mm} \times$ tebal $1 \mathrm{~mm}$

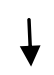

mengaduk powder dan liquid semen ionomer kaca sealant

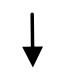

memasukkan hasil adukan ke dalam cetakan

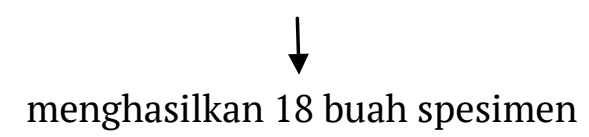

spesimen dimasukkan ke dalam desikator $\mathrm{T} 37^{\circ} \mathrm{C}$ selama 22 jam

spesimen dimasukkan lagi ke dalam desikator $\mathrm{T} 23^{\circ} \mathrm{C}$ selama 2 jam

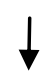

spesimen ditimbang berulangkali hingga didapatkan massa konstan

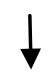

spesimen direndam di dalam aquabides $\mathrm{T} 37^{\circ} \mathrm{C}$ selama

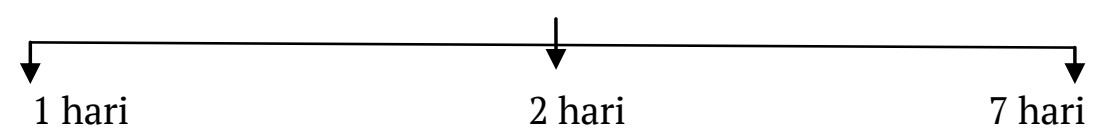

(6 spesimen)

(6 spesimen)

(6 spesimen)

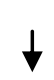


spesimen ditimbang berulangkali hingga didapakan massa konstan (M2)

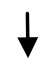

spesimen dimasukkan lagi ke dalam desikator $37^{\circ} \mathrm{C}$ selama 22 jam, kemudian

ke dalam desikator $23^{\circ} \mathrm{C}$ selama 2 jam

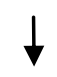

spesimen ditimbang berulangkali hingga didapatkan massa konstan (M3)

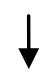

uji penyerapan dan kelarutan

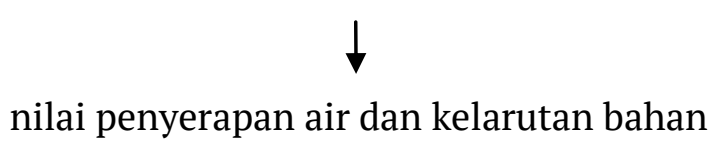

\section{HASIL DAN PEMBAHASAN}

\section{a. Hasil Penelitian}

Grafik 1 menggambarkan nilai penyerapan air (water sorption) pada 18 spesimen dengan 3 jenis lama perendaman. Dari grafik tersebut terlihat bahwa nilai penyerapan air menurun di hari kedua lalu meningkat hingga hari ketujuh dengan rata-rata nilai penyerapan air seteleh direndam selama 1 hari adalah $42,68 \mu \mathrm{g} /$ $\mathrm{mm}^{3}, 2$ hari sebesar $40,53 \mu \mathrm{g} / \mathrm{mm}^{3}$, dan 7 hari sebesar $42,99 \mu \mathrm{g} / \mathrm{mm}^{3}$.

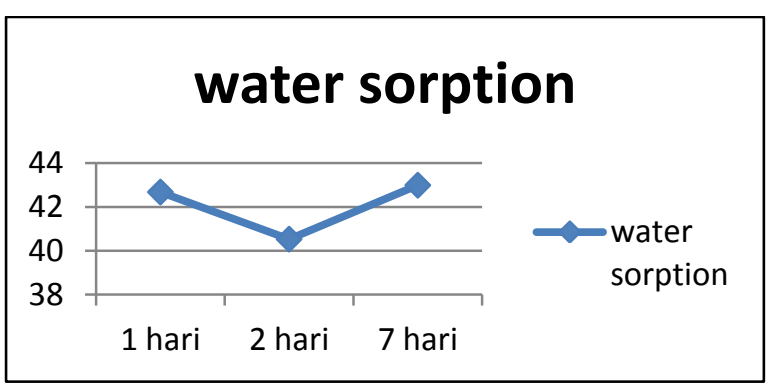

Grafik 1. Nilai Rata-rata Penyerapan Air (Water Sorption)

Grafik 2 menggambarkan nilai kelarutan bahan (water solubility) pada 18 spesimen dengan 3 jenis lama perendaman. Dari grafik tersebut terlihat bahwa nilai kelarutan bahan menurun di hari kedua lalu meningkat hingga hari ketujuh dengan rata-rata nilai kelarutan bahan seteleh

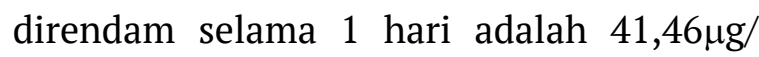
$\mathrm{mm}^{3}, 2$ hari sebesar $39,39 \mu \mathrm{g} / \mathrm{mm}^{3}$, dan 7 hari sebesar $41,91 \mu \mathrm{g} / \mathrm{mm}^{3}$. 


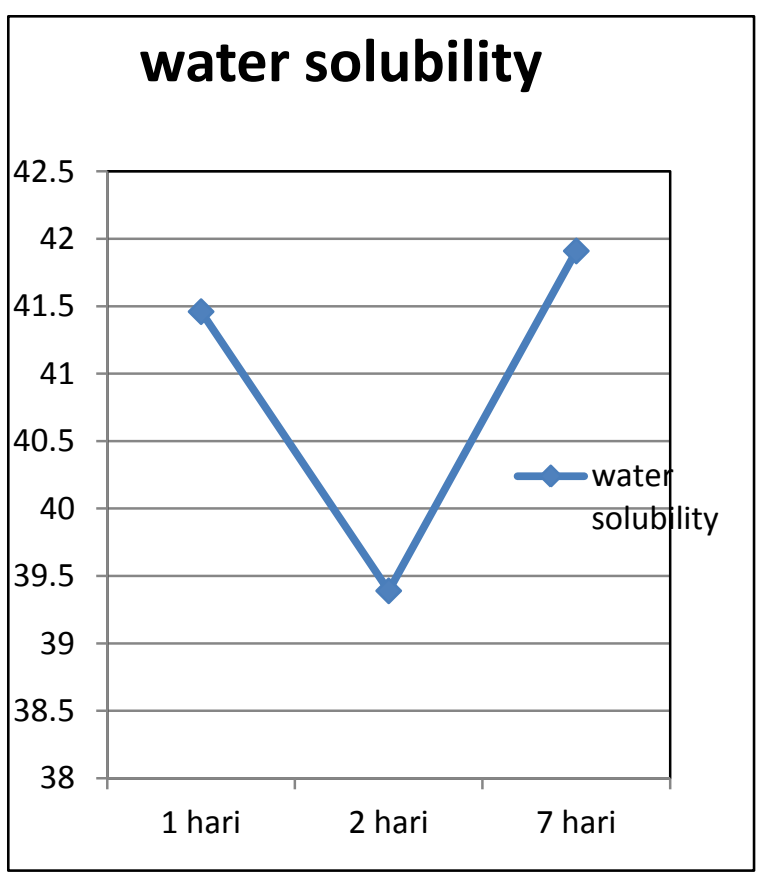

Grafik 2. Nilai Rata-rata Kelarutan Bahan (Water Solubility)

Jika dilihat secara bersamaan, antara nilai penyerapan air dan kelarutan bahan, Nampak pada grafik 3 berikut ini.

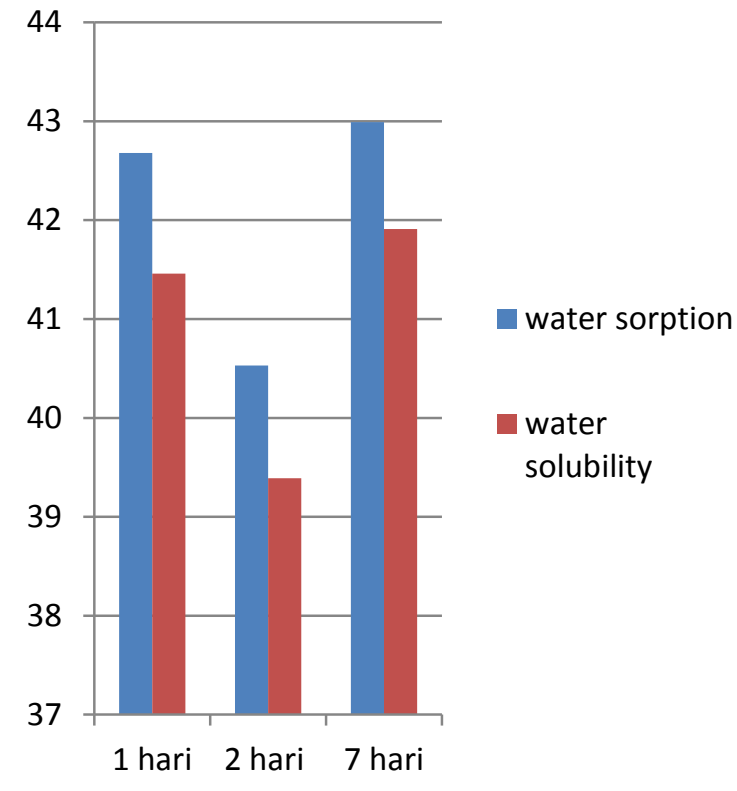

Grafik 3. Nilai Rata-rata Penyerapan Air dan Kelarutan Bahan

Dalam melakukan pengolahan data ini, dibantu dengan program statistik menggunakan SPSS 21. Dari uji statistik yang dilakukan, diharapkan dapat diketahui apakah terdapat perbedaan bermakna untuk nilai penyerapan air dan kelarutan bahan dengan lama perendaman 1 hari, 2 hari dan 7 hari.

Berdasarkan uji homogenitas varians, sebaran data yang diperoleh adalah homogen $(p>0,05)$. Dari hasil uji normalitas Kolmogorov - Smirnov menunjukkan bahwa nilai penyerapan air dan kelarutan bahan untuk semua waktu perendaman mempunyai nilai signifikansi (p) > 0, 05, yang berarti sebaran data di dalam masing-masing kelompok spesimen tersebut adalah normal.

Syarat yang harus dipenuhi dalam melakukan uji non-parametric Kruskal Wallis adalah memiliki > 2 kelompok, merupakan data numerik dan nonparametric. Pada hasil uji Kruskal - Wallis untuk penyerapan air, diperoleh nilai $\mathrm{p}=$ 0,676 ( $p>0,05)$ yang berarti tidak terdapat perbedaan bermakna untuk waktu perendaman 1 hari, 2 hari ataupun 7 hari. Demikian juga pada hasil uji Kruskal - 
Wallis untuk kelarutan bahan, diperoleh nilai $p=0,812(p>0,05)$ yang berarti tidak terdapat perbedaan bermakna untuk waktu perendaman 1 hari, 2 hari ataupun 7 hari. Hal tersebut nampak dari nilai rata-rata penyerapan air dan kelarutan bahan yang didapat dari hasil penelitian ini, dimana memang hanya terdapat sedikit selisih nilai dari 1 hari, 2 hari maupun 7 hari perendaman.

Secara statistik dapat dikatakan bahwa semua nilai signifikansi penyerapan air dan kelarutan bahan antar kelompok perlakuan memiliki nilai $\mathrm{p}>0,05$ yang berarti bahwa tidak terdapat perbedaan bermakna antar setiap kelompok perlakuan.

\section{b. Pembahasan}

Suatu bahan yang direndam di dalam air akan mengalami dua mekanisme yang berbeda. Pertama, penyerapan air, yang menyebabkan pembengkakan dan meningkatnya massa dan yang kedua, kelarutan bahan dalam air, terlepasnya komponen dari monomer yang tidak bereaksi yang menyebabkan berkurangnya massa (Archegas et al, 2008).

Semen Ionomer kaca sensitif terhadap erosi air, fenomena ini diperburuk di oleh kondisi lingkungan mulut dengan adanya senyawa yang bersifat agresif pada saliva. Keberhasilan klinis semen ionomer kaca tergantung pada perlindungan awal yang diberikan untuk menghindari terjadinya hidrasi dan dehidrasi. Deniz dkk dalam Ghanim (2009) menemukan bahwa tingginya level kelarutan dihubungkan dengan awal terpaparnya bahan semen dengan air setelah diaduk. Semen ionomer kaca sebagai perekat sangat sensitif dengan air selama 6 menit pertama setelah pengadukan.

Sensitivitas terhadap air yang dimiliki oleh semen ionomer kaca sealant (Fuji VII) yang menggunakan penyinaran adalah terjadi pada 3 menit pertama setelah aplikasi bahan dan yang tidak menggunakan penyinaran adalah pada 2 menit pertama setelah aplikasi (Dental, 2008). Berdasarkan hasil penelitian Ghanim (2009), diketahui bahwa nilai penyerapan air semen ionomer kaca sebagai bahan restorasi adalah sebesar $219,17 \mu \mathrm{g} / \mathrm{mm}^{3}$ dan nilai kelarutan bahan semen ionomer kaca sebagai bahan restorasi adalah sebesar $44,82 \mu \mathrm{g} / \mathrm{mm}^{3}$

Hasil penelitian ini menunjukkan bahwa nilai penyerapan air dan kelarutan bahan pada semen ionomer kaca sebagai bahan penutup fisur lebih rendah dibandingkan dengan semen ionomer kaca sebagai bahan restorasi, dengan kata lain, semen ionomer kaca sebagai bahan penutup pit dan fisur gigi lebih tidak 
menyerap air dan lebih tidak larut dalam air jika dibandingkan dengan semen ionomer kaca sebagai bahan restorasi. Selain itu juga terlihat dari hasil uji statistik yang memperlihatkan bahwa walaupun ada perbedaan nilai penyerapan air dan kelarutan bahan untuk perendaman selama 1, 2 dan 7 hari, namun perbedaan tersebut tidaklah bermakna, atau dengan kata lain, walaupun direndam sampai 7 hari, semen ionomer kaca tetaplah stabil sebagai bahan penutup pit dan fisur gigi.

Namun jika dibandingkan dengan bahan penutup fisur gigi dari resin komposit, semen ionomer kaca lebih menyerap air dan lebih mudah larut dalam air. Nilai penyerapan air resin komposit sebagai penutup fisur gigi adalah $37,4 \mu \mathrm{g} /$ $\mathrm{mm}^{3}$ dan nilai kelarutan bahannya $4,5 \mu \mathrm{g} /$ $\mathrm{mm}^{3}$ (Hertanto, 2008).

Semen ionomer kaca sebagai penutup pit dan fisur gigi dirancang untuk gigi dengan indikasi remineralisasi maupun gigi sehat yang membutuhkan proteksi dari kemungkinan terjadinya karies. Gigi-gigi dengan indikasi tersebut seringkali dimiliki oleh anak-anak dalam masa gigi bercampur, yang tentunya memiliki produksi saliva lebih banyak daripada orang dewasa. Bahan penutup fisur gigi sebaiknya adalah bahan yang bersifat penyerapan air dan kelarutan bahannya rendah. Untuk saat ini, yang bisa memenuhi ketentuan tersebut adalah resin komposit (Veranes, 2006). Namun perlu diingat bahwa dalam pengaplikasian resin komposit sebagai penutup pit dan fisur gigi, membutuhkan pengetsaan email, yang artinya ada pengikisan sebagian kecil email. Selain itu, resin komposit tidak melepaskan fluor yang bisa menjadi agen pencegah karies gigi. Semen ionomer kaca memiliki nilai penyerapan air dan kelarutan bahan yang lebih tinggi dari resin komposit, namun dalam pengaplikasiannya tidak mengikis email dan justru melepaskan fluor untuk mencegah karies gigi.

\section{KESIMPULAN}

Dari hasil penelitian ini dapat disimpulkan bahwa nilai penyerapan air semen ionomer kaca sebagai penutup pit \& fisur gigi mengalami penurunan hingga hari kedua lalu meningkat hingga hari ketujuh, dengan rata-rata penyerapan air untuk perendaman selama 1 hari sebesar $42,68 \mu \mathrm{g} / \mathrm{mm}^{3}, 2$ hari $40,53 \mu \mathrm{g} / \mathrm{mm}^{3}$ dan 7 hari $42,99 \mu \mathrm{g} / \mathrm{mm}^{3}$, dan untuk nilai kelarutan dalam air semen ionomer kaca sebagai penutup pit \& fisur gigi 
mengalami penurunan hingga hari kedua lalu meningkat hingga hari ketujuh, dengan rata-rata kelarutan bahan untuk perendaman selama 1 hari sebesar $41,46 \mu \mathrm{g} / \mathrm{mm}^{3}, 2$ hari $39,39 \mu \mathrm{g} / \mathrm{mm}^{3}$ dan 7 hari $41,91 \mu \mathrm{g} / \mathrm{mm}^{3}$, selain itu tidak terdapat perbedaan yang signifikan untuk nilai penyerapan air dan kelarutan bahan selama masa perendaman 1,2 dan 7 hari.

Melalui hasil penelitian ini dapat disarankan bahwa dalam pengaplikasian semen ionomer kaca sebagai penutup pit dan fisur gigi harap diperhatikan dalam pemberian varnish atau pelindung agar mengurangi terjadinya penyerapan air dan kelarutan bahan. Selain itu, pit dan fisur gigi yang sudah diberi penutup, hendaknya dikontrol 3 bulan kemudian untuk mengetahui apakah penutupnya masih utuh atau sudah rusak maupun lepas. Penulis menganjurkan agar ada penelitian lanjutan untuk mengetahui nilai penyerapan air dan kelarutan semen ionomer kaca sebagai penutup pit dan fisur gigi jika direndam di dalam saliva buatan selama lebih dari 7 hari.

\section{REFERENCES}

Anonymous. (2015). Pit and Fissure Sealant, tersedia

di http://www.healthyteeth.org/prev ention/pitfissure.html disitasi pada 6 Juni 2015.
Agustiono, P., Irnawati, D., (1997). Pola Kelarutan dan penyerapan Air pada Bahan Tumpatan Gigi Hibrida Semen Ionomer Kaca dan Resin komposit Aktivasi Sinar tampak Jurnal Kedokteran Gigi Universitas Indonesia. 1997; 4 Edisi Khusus KPPIKG.

Anusavice, K.J. (1994). Ilmu Bahan Kedokteran Gigi, EGC, Jakarta.

Archegas, L. R, dkk. (2008). Sorption and Solubility of Composites Cured with Quartz-tunsten Halogen and Light Emitting Diode Light Curing Units, Journal Contemporary Dental Practice, 2008 February.

Baum, L. (1997). Buku Ajar Ilmu Konservasi Gigi, EGC, Jakarta.

Cefaly, D.F., dkk. (2006). Water Sorption of Resin-Modified Glass Ionomer Cements Photoactivated with LED, Brazilian Oral Research, 2006; 20 (4)

Combe, E.C. (1992). Sari Dental Material, terjemahan, Balai Pustaka, Jakarta.

Craig, R.G. (1979). Dental Materials, Mosby Company, London.

Dahlan, S. (2006). Statistika untuk Kedokteran dan Kesehatan, PT. Arkansas, Jakarta. 
Department of Health North Sidney. (2008). Pit and Fissure Sealants : Use of in Oral Health Servoce NSW, diakses dari http://www.health.nsw.gov.au/po licies/pd/2008/pdf/PD2008_028.p df pada 12 Juni 2015.

Gerdolle, D.A., dkk. (2008). Water Sorption and Water Solubility of Current Luting Cement: An in vitro study, Quintessence International, 2008 March.

Ghanim, A. (2010). Water Sorption and Solubility of Different Commercially Available Dental Cements, Medical Journal of Babylon, Volume 7 Issue 3 - 4, pp; 410- 421, Babylon University. Harris, N.O dan Garcia, F.G. (2004). Primary

Preventive Dentstry. 6th Ed., Pearson, New Jersey.

Hertanto, M. (2008). Pengaruh Lamanya Perendaman Resin Pit dan Fissure Sealant Di Dalam Air Terhadap Nilai Penyerapan dan Kelarutannya, Skripsi, Universitas Indonesia, Jakarta.

Kervanto, S. (2009). Arresting Occlusal Enamel Caries Lessions with Pit and Fissure Sealants, Academic Dissertation Faculty of Medicine,
University of Helsinki, diakses dari

http://oa.doria.fi/bitstream/handl e/10024/43707/arrestin.pdf?seque $\underline{\text { nce }=1}$ pada 6 Juni 2015

Keyf F, dkk. (2006). Water Sorption and Solubility of Different Luting and Restorative Dental Cements, Journal of Turkey Medical Science, 2006; 36 (1).

Lesser, D. (2001). An Overview of Dental Sealants, diakses dari http://www.adha.org/downloads/ sup_sealants.pdf pada 8 Juni $\underline{2015}$.

Mount, G.J dan Hume, W.R. (2005). Preservation and Restoration of Tooth structure, Knowledege Books and Software, Queensland. Noort, R.V. (2007). Introduction to Dental Materials 3rd Ed., Mosby Elsevier, London.

Nunn, J.H. (2000). British Society of Paediatric Dentistry: A Policy Document onFissure Sealants in Paediatric Dentistry, International Journal of Paediatric Dentistry, diakses dari http://www.bspd.co.uk/publicatio n-19.pdf pada 6 Juni 2015. 
Pinkham, J.R. (1994). Pediatric Dentistry,

Infancy Trough Adolescence 2nd
Ed., WB. Saunders Co., Philadelphia.

Ready to submit your research? Choose INFOKES and benefit from:

- fast, convenient online submission

- thorough peer review by experienced researchers in your field

- $\quad$ rapid publication on acceptance

- $\quad$ support for research data

- Open Access which fosters wider collaboration and increased citations

- maximum visibility for your research

At Health Polytechnic of Kupang, research is always in progress.

Learn more http://jurnal.poltekkekupang.ac.id/index.php/infokes 